\title{
Fatal Suicidal Attempt by Deliberate Ingestion of Nicotine- containing Solution in Childhood-onset Depression Mediated through Internet Suicide Guideline: A Case Report
}

\author{
Ashwini Kamble ${ }^{1}$, Praveen Khairkar ${ }^{2}$, Sri Prakash Kalantri ${ }^{3}$, Sneh Babhulkar ${ }^{4}$
}

\begin{abstract}
Nicotine is one of the most easily accessible, commonly abused drugs worldwide and if taken in overdose can cause serious clinical presentation, including cardiac arrhythmias and neurotoxicity mediated through oxidative stress. Its toxicity though rare can cause sudden deaths by cardiovascular arrest, respiratory muscle paralysis, and/or central respiratory failure. Here, we describe a case of intentional fatal ingestion of nicotine sulfate decoction used as a mean for fatal suicidal attempt by a 15-year-old adolescent male who was suffering from childhoodonset depression since about 3 months. He developed drooling of saliva, syncopal attacks, paroxysmal episodes of hematemesis, abdominal pain, signs and symptoms of hypoxia, nonfatal atrial tachycardia, and encephalopathy after ingestion of heavy dose of nicotine-containing concoction; however, he recovered successfully within 24-48 hours without any significant cardiac, respiratory, or neurological deficits (except short-term verbal memory). Authors discussed the details of management and reasons behind the reversible encephalopathy and molecular mechanism of nicotine toxicity.

Keywords: Acute encephalopathy with biphasic seizures and restricted diffusion, Children, Intensive care, Molecular mechanism, Nicotine toxicity, Suicidality.

Indian Journal of Critical Care Medicine (2020): 10.5005/jp-journals-10071-23524
\end{abstract}

\section{INTRODUCTION}

Nicotine, a lipid-soluble alkaloid obtained from the dried leaves of Nicotiana tabacum ${ }^{1}$ and although one of the most toxic drugs of abuse, it had rarely led to documented fatalities. Greenland et al. $^{2}$ published a meta-analysis in 1998 to assess the incidence of adverse effects associated with transdermal nicotine patch from 47 reports of 35 clinical trials, which mostly discussed about minor adverse effects and notably cardiovascular outcomes including stroke. Although rare, an acute ingestion of large amount of nicotine can produce rapid and dramatic toxicity.

In 2004, Rogers et al. ${ }^{3}$ reported first ever case report of ingestion of nicotine sulfate solution resulting in severe hypoxia and irreversible encephalopathy. Subsequently, in 2010, Schneider et al. ${ }^{4}$ documented similar case of 67-year-old man who tried to commit suicide by following the guidelines on an internet website. Last but not least, documentation in 2016 by Khan et al. ${ }^{5}$ reported nicotine toxicity in nursing home resident with dementia secondary to nicotine replacement therapy. Except these few rare documented cases, the literature has been relatively scarce and silent about nicotine toxicity on humans critically affecting the body systems. We hereby report a case of a 15-year-old adolescent boy suffering from major depression ingesting nicotine sulfate solution resulting in marked features of hypoxia, gastrointestinal toxicity, nonfatal atrial tachycardia, and reversible encephalopathy but fortunately recovered completely. We believe that this is the first ever report of planned suicidal attempt using nicotine containing solution from India surprisingly mediated through Internet suicide guideline and discussed the molecular mechanism behind such toxic effects on brain and heart.

\section{Case Description}

Master D, a 15-year-old, right-handed adolescent boy, was brought to emergency services of our tertiary-care hospital on last week
${ }^{1}$ Department of Biochemistry, Kamineni Institute of Medical Sciences, Narketpally, Nalgonda, Telangana, India

${ }^{2}$ Department of Psychiatry and Clinical Neurosciences, Kamineni Institute of Medical Sciences, Narketpally, Nalgonda, Telangana, India ${ }^{3}$ Department of Medicine, Mahatma Gandhi Institute of Medical Sciences, Sevagram, Maharashtra, India

${ }^{4}$ Department of Psychiatry, BJ Medical College, Pune, Maharashtra, India

Corresponding Author: Praveen Khairkar, Department of Psychiatry and Clinical Neurosciences, Kamineni Institute of Medical Sciences, Narketpally, Nalgonda, Telangana, India, Phone: +91 9890008416, e-mail: praveen.khairkar280@gmail.com

How to cite this article: Kamble A, Khairkar P, Kalantri SP, Babhulkar S. Fatal Suicidal Attempt by Deliberate Ingestion of Nicotinecontaining Solution in Childhood-onset Depression Mediated through Internet Suicide Guideline: A Case Report. Indian J Crit Care Med 2020;24(8):719-721.

Source of support: Nil

Conflict of interest: None

of January 2017 by his parents in a state of unconsciousness precipitated by three to four bouts of vomiting and hematemesis, after having consumed about $100 \mathrm{~mL}$ of resinous decoction of concentrated nicotine about half an hour before reaching hospital with the intent of killing himself. Reportedly, the patient went through internet for preparing concentrated nicotine decoction for intentional suicidal harm and one day he soaked about $100 \mathrm{~g}$ of tobacco for 3 days without letting anybody in family to discover it. He let evaporate all extracts and then added a glass of water. $\mathrm{He}$ did not share his plan with any of the family member in ensuing days, remained alone, sad, and his parents reported that he was

o The Author(s). 2020 Open Access This article is distributed under the terms of the Creative Commons Attribution 4.0 International License (https://creativecommons. org/licenses/by-nc/4.0/), which permits unrestricted use, distribution, and non-commercial reproduction in any medium, provided you give appropriate credit to the original author(s) and the source, provide a link to the Creative Commons license, and indicate if changes were made. The Creative Commons Public Domain Dedication waiver (http://creativecommons.org/publicdomain/zero/1.0/) applies to the data made available in this article, unless otherwise stated. 
using excessive Internet reading whenever they approached him. He avoided food, stopped enjoying all his previous pleasurable activities, could not concentrate on studies, and would talk bleak pessimistic ideations. There was no previous, past, or family history of suicidal attempt, neither was any psychotic, manic, and obsessive or other substance use history. On physical examination, he had pallor, tachycardia, ectopic beats, drooling of saliva from his mouth, hypotension $(70 / 50 \mathrm{~mm}$ of $\mathrm{Hg}$ ), profuse perspiration, breathing difficulty, and stuporous state. Within next 10 minutes, he again had two episodes of nonbilious, nonprojectile vomiting without blood. There was no history of head injury, convulsions, fasciculation, bronchorrhea, incontinence of urine, or feces.

His blood and gastric aspirate were immediately sent to our institutional toxicology laboratory for poisoning analysis. He was intubated and gastric lavage using activated charcoal was done, and his complete blood counts and renal and liver function tests were found to be normal. However, his electrocardiogram showed transient atrial ectopy and tachycardia.

He regained his consciousness within 30-40 minutes of intubation but was disoriented, confused, agitated, and restless, and his mood was labile. He continued to have nausea, palpitation, headache, drooling of saliva, generalized weakness and fluctuating level of sensorium with altered sleep-wake cycle rhythm for first 24 hours, but his magnetic resonance imaging of the brain was normal, and his intubation was taken off the next day. $\mathrm{He}$ repeatedly expressed ideas of hopelessness, worthlessness, and did not have guilt for his suicidal act from day 2 of his recovery onward. Psychiatric consultation was sought, and it became evident that he was suffering from severe depressive episode without significant improvement since last 3 months. His Beck's depression inventory score was 28 and IPDE (International Personality Disorder Examination)-based personality assessment revealed shades of impulsive and histrionic traits. High-risk suicidal management was done. He was started on capsule venlafaxine $75 \mathrm{mg} /$ day, (and was gradually increased to $225 \mathrm{mg} /$ day) with low-dose risperidone of $1 \mathrm{mg} /$ day. He was discharged on day 14 with more than $70-80 \%$ of improvement on Beck's depression inventory. Over more than a year down, all his medications have been stopped, and he has been symptom free since then.

\section{Discussion}

To the best of our knowledge, this is the first ever reported case of nicotine poisoning from India. The index case showed typical presentation of nicotine toxicity, and had it not been treated in time, he might have developed irreversible encephalopathy as documented by Rogers et al. ${ }^{3}$ or to death as reported by Solarino et al. ${ }^{6}$ Unlike to their cases, our index patient clearly has reversible encephalopathy and nonfatal cardiac arrhythmias, which may be either because he consumed less quantity or because most of resinous decoction might have expelled from gastrointestinal tract by repeated bouts of vomiting and early intervention of activated charcoal lavage. Further, our index patient was brought within half an hour and consumed less quantity compared to latter, and therefore the toxicity was perhaps less pronounced. Toxic effects of nicotine poisoning can be deadly, and sudden death can be caused by cardiovascular arrest, respiratory muscle paralysis, and/or central respiratory failure. The fatal toxicities though rare are reported as early as 1991 by Lavoie and Harris ${ }^{7}$ to as late as 2010 Corkery et al. ${ }^{8}$
Most deaths occur within few minutes of ingestion and recovery usually occurs if patient survives for first 1-4 hours. ${ }^{9}$

The lethal dose $\left(\mathrm{LD}_{50}\right)$ of nicotine is $50 \mathrm{mg} / \mathrm{kg}$ for rats and $3 \mathrm{mg} /$ $\mathrm{kg}$ for mice but even $0.5-1.0 \mathrm{mg} / \mathrm{kg}$ can be a lethal dosage for adult humans. ${ }^{10,11}$ Nicotine therefore has a high toxicity in comparison to many other alkaloids, such as cocaine, which has an $\mathrm{LD}_{50}$ of 95.1 $\mathrm{mg} / \mathrm{kg}$ when administered to mice. The generally recognized fatal blood level of nicotine is $>5 \mathrm{mg} / \mathrm{L} .{ }^{10}$ The case reported by Schneider et al. ${ }^{4}$ observed serum nicotine levels of $322 \mu \mathrm{g} / \mathrm{L}$, and cotinine levels were $9092 \mu \mathrm{g} / \mathrm{L}$, almost 3 hours after the consumption of 300 $\mathrm{g}$ of soaked tobacco. Because, in qualitative analysis, we could find out the presence of cotinine, a metabolite of nicotine in saliva and serum, which constitutes the commonly used objective method of ascertaining nicotine exposure, however, the quantitative analysis of blood levels could not be made available. This made the comparative analogy difficult with previously published studies as far as serum nicotine levels are concerned. Mehta et al. reported presentations of cardiac arrhythmia following intravenous nicotine in their weekly 52 experiments in 16 anesthetized dogs and reported supraventricular bradycardia in $83 \%$, atrial ectopy in $67 \%$, sinus arrest in $50 \%$, and atrial tachycardia in $25 \% .^{12}$ Interestingly, the mechanism of nicotine toxicity is not clearly delineated; however, considerable evidence points to the involvement of oxidative stress, reactive oxygen species, lipid peroxidation, and DNA damage. ${ }^{13}$ These events might be operated via iminium metabolites through electron transfer with redox cycling to produce radical entities. The cationic metabolites arise from oxidation of nicotine itself and protonation of myosmine that originates from nor-nicotine via demethylation causing destruction of neurons and astrocytes that manifested as encephalopathy. This is slightly different from the pathogenesis of reversible epileptic or hepatic encephalopathy, as cytokine storm of interleukins are responsible in epileptic process, while increased ammonia causing osmotic imbalance and ultimately brain edema in hepatic reversible or irreversible encephalopathy depending on severity of damage. ${ }^{14,15}$

\section{Conclusion}

Nicotine is one of the most easily accessible, commonly abused drugs worldwide and if taken in overdose can cause serious clinical presentation including cardiotoxicity and neurotoxicity mediated through oxidative stress. Available electronic Internet database resources that helps us in enhancing our ways of awareness about effectiveness of psychotropic drugs and innovative prevention modalities for various neuropsychiatric disorder(s), but on the contrary it also allows young children and adolescents in who rising incidents of impulsivity and suicidality are happening to gain access for committing experimental punitive mode; ${ }^{16}$ currently, there are no food and drug administration or other federal regulations about e-cigarettes or regarding liquid nicotine toxicity. Therefore, need to transpire the formulation of treatment guidelines or recommendations in clinical and/or emergency medicine for its appraisal is warranted in the near future.

\section{Declaration of Patient Consent}

The authors certify that they have obtained all appropriate patient consent forms. In the form, patient's parents have given their consent for the clinical information to be reported in journal. The patient and his parents understand that their names and initials 
will not be published and due efforts will be made to conceal their identity, nut anonymity cannot be guaranteed.

\section{References}

1. Stolerman IP, Jarvis MJ. The scientific case that nicotine is addictive. Psychopharmacol 1995;117(1):2-10. DOI: 10.1007/BF02245088.

2. Greenland S, Satterfield MH, Lanes SF. A meta-analysis to assess the incidence of adverse effects associated with the transdermal nicotinic patch. Drug Safety 1998;18(4):297-308. DOI: 10.2165/00002018199818040-00005.

3. Rogers AJ, Denk LD, Wax PM. Catastrophic brain injury after nicotine insecticide ingestion. J Emerg Med 2004;26(2):169-172. DOI: 10.1016/j. jemermed.2003.05.006.

4. Schneider S, Diederich N, Appenzeller B, Schartz A, Lorang C, Wennig R. Internet suicide guidelines: report of a life-threatening poisoning using tobacco extract. J Emerg Med 2010;38(5):610-613. DOI: 10.1016/j.jemermed.2008.10.023.

5. Khan S, Blanton MP, Chavez M. Nicotine toxicity in a nursing home resident with dementia secondary to nicotine replacement treatment. Prim Care Companion CNS Disord 2016;18(3):10-13. DOI: 10.4088/PCC.15I01882

6. Solarino B, Rosenbaum F, Riesselmann B, Buschmann CT, Tsokos M. Death due to ingestion of nicotine-containing solution: case report and review of the literature. Forensic Sci Int 2010;25(195):19-22. DOI: 10.1016/j.forsciint.2009.11.003.

7. Lavoie FW, Harris TM. Fatal nicotine ingestion. J Emerg Med 1991;9(3):133-136. DOI: 10.1016/0736-4679(91)90318-A.
8. Corkery JM, Button J, Vento AE, Schifano F. Two UK suicides using nicotine extracted from tobacco employing instructions available on the internet. Forensic Sci Int 2010;15(3):9-13. DOI: 10.1016/ j.forsciint.2010.02.004.

9. Patty's Industrial Hygeine and Toxicology, In: Clayton DG, Clayton FE, ed. 4th ed., New York: John Wiley \& Son's Inc.; 1994. p. 3378.

10. Okamoto M, Kita T, Okuda H, Tanaka T, Nakashima T. Effects of aging on acute toxicity of nicotine in rats. Pharmacol Toxicol 1994;75(1):1-6. DOI: 10.1111/j.1600-0773.1994.tb00316.x.

11. Woolf A, Burkhart K, Caraccio T, Litovitz T. Self-poisoning among adults using multiple transdermal nicotine patches. J Toxicol Clin Toxicol 1996;34(6):691-698. DOI: 10.3109/15563659609013830.

12. Mehta MC, Jain AC, Mehta A, Billie M. Cardiac arrhythmias following intravenous nicotine: experimental study in dogs. J Cardiovasc Pharmacol Ther 1997;2(4):291-298. DOI: 10.1177/1074248497 00200407.

13. Kovacic $\mathrm{P}$, Cooksy A. Iminium metabolite mechanism for nicotine toxicity and addiction: oxidative stress and electron transfer. Med Hypothesis 2005;64(1):104-111. DOI: 10.1016/j.mehy.2004. 03.048 .

14. Vitaliti G, Pavone P, Marino S, Saporito MA, Corsello G, Falsaperla R. Molecular mechanism involved in pathogenesis of early-onset epileptic encephalopathy. Front Mol Neurosci 2019;15(12):118-123. DOI: 10.3389/fnmol.2019.00118.

15. Jalan R, Shawcross D, Davies N. The molecular pathogenesis of hepatic encephalopathy. Int J Biochem Cell Biol 2003;35(8):1175-1181. DOI: 10.1016/S1357-2725(02)00396-5.

16. Kim JW. Liquid nicotine toxicity. Ped Emergency Care 2015;31(7): 517-521. DOI: 10.1097/PEC.0000000000000486. 